\title{
Fabrication and Characterization of 1200V 40A 4H-SiC SBD
}

\author{
Gang Chen ${ }^{1,2, a}$, Yinglu Fang ${ }^{2}$, Yun $\mathrm{Li}^{1}$, Lin Wang ${ }^{2}$, Song Bai ${ }^{1,2}$, Ao $\mathrm{Liu}^{2}$, \\ Runhua Huang ${ }^{2}$, Yonghong $\mathrm{Tao}^{2}$, Zhifei Zhao ${ }^{1}$ \\ ${ }^{1}$ State Key laboratory of Wide-bandgap Semiconductor Power Electronics, Nanjing, China \\ ${ }^{2}$ Nanjing Electronic Devices Institute, Nanjing, China \\ ${ }^{a}$ E-mail: steelchg@163.com
}

Keywords: 4H-SiC, SBD, ohmic

Abstract: High voltage 4H-SiC Ti schottky junction barrier schottky (JBS) diode with breakdown voltage of $1200 \mathrm{~V}$ and forward current of $40 \mathrm{~A}$ has been fabricated. A low reverse leakage current below $1.02 \times 10^{-4} \mathrm{~A}$ or $4.08 \times 10^{-4} \mathrm{~A} / \mathrm{cm}^{2}$ at the $25{ }^{\circ} \mathrm{C}$ and the reverse bias voltage of $1200 \mathrm{~V}$ has been obtained. The forward on-state current was $40 \mathrm{~A}$ at $\mathrm{V}_{\mathrm{F}}=1.61 \mathrm{~V}$ with $25^{\circ} \mathrm{C}$ and at $\mathrm{V}_{\mathrm{F}}=1.89 \mathrm{~V}$ with $100^{\circ} \mathrm{C}$. The chip is $5 \mathrm{~mm} \times 5 \mathrm{~mm}$ and the active-region is $3.8 \mathrm{~mm} \times 3.8 \mathrm{~mm}$. The turn-on voltage is about $0.83 \mathrm{~V}$. The on-state resistance is $4 \mathrm{~m} \Omega \cdot \mathrm{cm}^{2}$. The doping and thickness of the $\mathrm{N}$-type drift layer and the device structure have been performed by numerical simulations. The SiC JBS devices have been fabricated and the processes were in detail. By using Ti/Ni/Au multilayer metal structure, the double side $\mathrm{Au}$ process of $4 \mathrm{H}-\mathrm{SiC}$ JBS diode is formed.

\section{Introduction}

The power devices are mainly fabricated using silicon as the semiconductor material. Si device design and fabrication technology has matured over the past six decades. $4 \mathrm{H}-\mathrm{SiC}$ has been shown to have tremendous potential for high power electronic devices. ${ }^{[1]} \mathrm{SiC}$ power devices has been a stable segment in the power electronics market in recent years. We have already reported a high-voltage $(>2$ $\mathrm{kV}$ ) $\mathrm{Ti} / 4 \mathrm{H}-\mathrm{SiC} \mathrm{SBD}$ fabricated on $12 \mathrm{um}$ thick $4 \mathrm{H}-\mathrm{SiC}$ epilayer with $\mathrm{B}+$ implantation edge termination and field plate technology. ${ }^{[2]}$

In this article, we report our progress research on epitaxial thickness, doping and DC and experimental results of $1200 \mathrm{~V} 40 \mathrm{~A} 4 \mathrm{H}-\mathrm{SiC}$ SBD. The fabrication process is also described in detail.

\section{Design and Experimental}

High-voltage $1200 \mathrm{~V} 40 \mathrm{~A} 4 \mathrm{H}-\mathrm{SiC}$ diodes have been fabricated in a newly developed processing sequence, using standard silicon process equipment. Epitaxial layers grown by chemical vapor deposition (CVD) on commercial $4 \mathrm{H}-\mathrm{SiC}$ substrates were used as starting material for implanted p+-n--n+ merged pn-Schottky (MPS) diodes, together with additional test structures. ${ }^{[3]}$ The epitaxial structure view and thickness map of a $4 \mathrm{H}-\mathrm{SiC}$ epitaxial wafer of $1200 \mathrm{~V} 40 \mathrm{~A}$ SBD are shown in Fig. 1. The average thickness of $4 \mathrm{H}-\mathrm{SiC}$ epitaxial layer is $11.6 \mathrm{um}$, the minimum value is 11.1 and the maximu value is $12.2 \mathrm{um}$. A successful design of the SiC SBD is shown in Fig. 2. The SiC SBDs are fabricated on a highly doped $\mathrm{n}+4^{\circ}$ off-axis $\mathrm{Si}$-face 4 inch $4 \mathrm{H}-\mathrm{SiC}$ substrate with epitaxially grown $\mathrm{n}^{+}$ buffer, $\mathrm{n}^{-}$drift layers. The Schottky contact layer is $11.6 \mu \mathrm{m}$ thick and doped to $\mathrm{n}^{-}=6.5 \times 10^{15} \mathrm{~cm}^{-3}$ for $\mathrm{Ti} / \mathrm{SiC}$ Schottky contact formation. The $\mathrm{n}^{+}$buffer layer is $1 \mu \mathrm{m}$ thick and doped to $1 \times 10^{18} \mathrm{~cm}^{-3}$. The $\mathrm{n}^{-}$type drift layer is designed to block over $1200 \mathrm{~V}$. Both Schottky and PN diodes were processed on the same wafer to fabricate Schottky contacts on n-type epilayer and ohmic contacts on implanted p-type regions, respectively. ${ }^{[5]}$ Optimize the device's structure design through a finite element analysis and adopt 10 terminal protection guard rings according to the results. The width of the Schottky contact surface in active region is $5 \mathrm{um}$ and the width of implanted $\mathrm{P}^{+}$region is $1 \mathrm{um}$. The width of 10 terminal protection guard rings is $3 \mathrm{um}$ and all the rings are in the 70um width region. The terminal protection guard rings are formed with $\mathrm{Al}^{+}$implanted simultaneously with the $\mathrm{P}^{+}$region of the active region. An activation annealing was carried out at $1850^{\circ} \mathrm{C}$ for $3 \mathrm{~min}$ in $\mathrm{Ar}$ ambient. The $\mathrm{n}^{-}$ 
Schottky regions and $\mathrm{p}^{+}$regions are simultaneously metallized with $\mathrm{Ti}$ with the e-beam evaporation and annealed at $450{ }^{\circ} \mathrm{C} .{ }^{[4]}$ Excluding the bonding pads and edge termination regions, the single chip has a total area of $25 \mathrm{~mm}^{2}\left(5 \times 5 \mathrm{~mm}^{2}\right)$. The back side Ni ohmic metal layers are annealed at $900{ }^{\circ} \mathrm{C}$ with $\mathrm{n}^{+} 4 \mathrm{H}-\mathrm{SiC}$ to form nickel silicide ohmic contacts. By using Ti/Ni/Au multilayer metal structure, the double side $\mathrm{Au}$ process of $4 \mathrm{H}-\mathrm{SiC}$ JBS diode is formed.

\begin{tabular}{|c|}
\hline $11 \mathrm{um}, 6.5 \mathrm{E} 15, \mathrm{~N}^{-} \mathrm{dr}$ ift \\
\hline 1um, 1E18, $\mathrm{N}^{+}$buffer \\
\hline $4 \mathrm{H}-\mathrm{SiC} \mathrm{N}^{+}$substrate \\
\hline
\end{tabular}

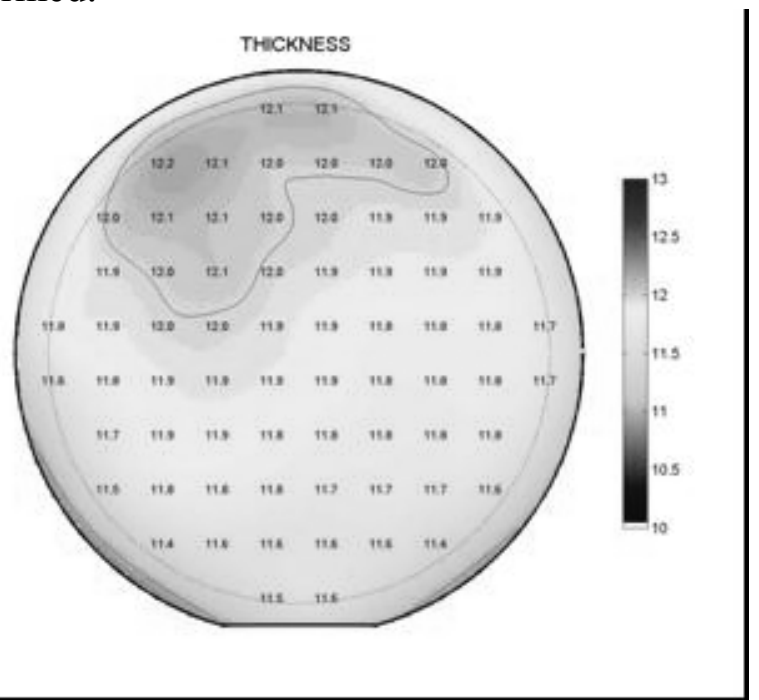

Fig. 1 Cross sectional view and thickness map of a 4H-SiC epitaxial wafer for 1200V 40A SBDs

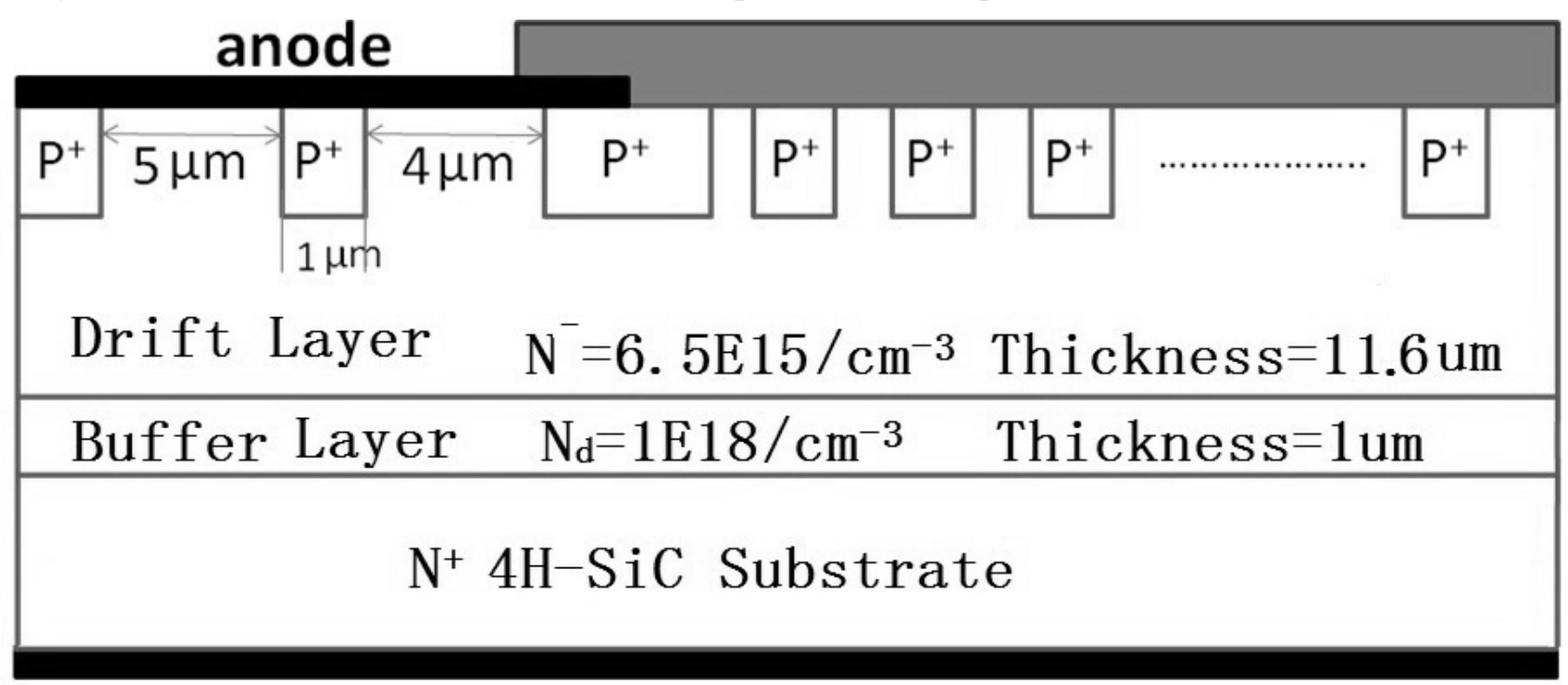

\section{Cathode}

Fig. 2 A designed image of the 1200V 40 A SiC SBD

\section{Results and discussions}

Tektronix 370 is used to measure the devices. From Fig. 3, we can know that the $1200 \mathrm{~V} 40 \mathrm{~A} \mathrm{SiC}$ SBD device yielded a forward current $40 \mathrm{~A}$ at a forward voltage of $1.61 \mathrm{~V}$ at $25{ }^{\circ} \mathrm{C}, 1.67 \mathrm{~V}$ at $50{ }^{\circ} \mathrm{C}$, $1.79 \mathrm{~V}$ at $75{ }^{\circ} \mathrm{C}, 1.90 \mathrm{~V}$ at $100{ }^{\circ} \mathrm{C}$. The device has a specific on-resistance of $4 \mathrm{~m} \Omega \cdot \mathrm{cm}^{2}$ at $25{ }^{\circ} \mathrm{C}, 4.6$ $\mathrm{m} \Omega \cdot \mathrm{cm}^{2}$ at $50{ }^{\circ} \mathrm{C}, 5.35 \mathrm{~m} \Omega \cdot \mathrm{cm}^{2}$ at $75{ }^{\circ} \mathrm{C}, 6.1 \mathrm{~m} \Omega \cdot \mathrm{cm}^{2}$ at $100{ }^{\circ} \mathrm{C}$, considering the guarding rings area. From Fig. 4, we can know that, at the forward voltage of $1.5 \mathrm{~V}$, the $1200 \mathrm{~V} 40 \mathrm{~A} \mathrm{SiC} \mathrm{SBD}$ device yielded a forward current $34 \mathrm{~A}$ at $25{ }^{\circ} \mathrm{C}, 31 \mathrm{~A}$ at $50{ }^{\circ} \mathrm{C}, 26 \mathrm{~A}$ at $75{ }^{\circ} \mathrm{C}, 24 \mathrm{~A}$ at $100{ }^{\circ} \mathrm{C}$. During the temperture increased from $25{ }^{\circ} \mathrm{C}$ to $100{ }^{\circ} \mathrm{C}$, the degradation of the forward current is $30 \%$, the degradation of the forward voltage is $18 \%$, the degradation of the specific on-resistance is $52.5 \%$. The 1200 V 40 A SiC SBD devices are viable high temperature alternatives. As illustrated in Fig. 5, the room temperature $1200 \mathrm{~V} 40 \mathrm{~A} \mathrm{SiC} \mathrm{SBD}$ device's blocking voltage is $1200 \mathrm{~V}$ at reverse leakage 
current equal to $102 \mu \mathrm{A}$. More comprehensive test data taken at higher temperatures will be presented later.

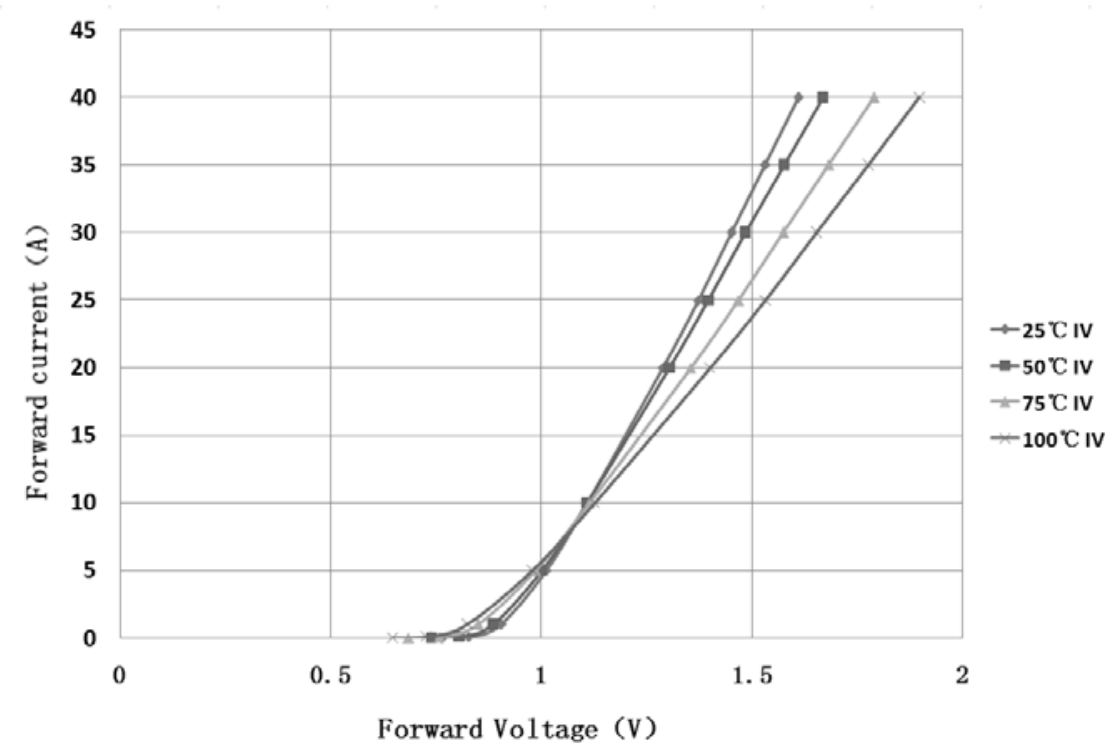

Fig. 3 Forward I-V characteristics up to $40 \mathrm{~A}$ with V $<2 \mathrm{~V}$ for $1200 \mathrm{~V} 40 \mathrm{~A}$ SiC SBD, temperature from $25{ }^{\circ} \mathrm{C}$ to $100^{\circ} \mathrm{C}$.

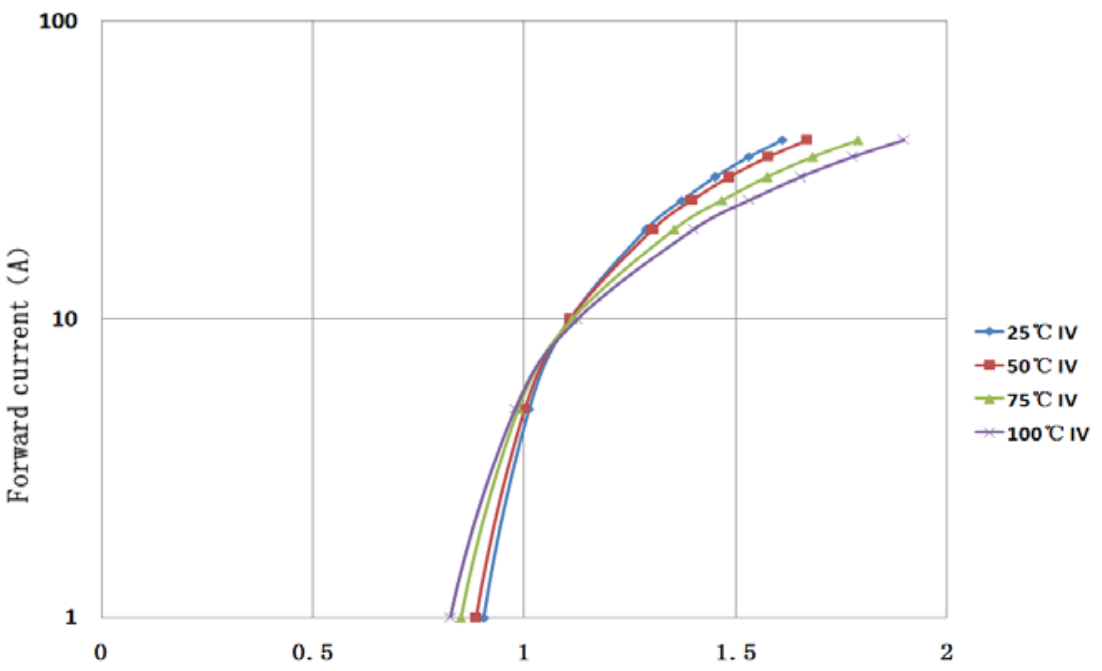

Forward Voltage (V)

Fig. 4 Logarithmic scale forward I-V characteristics 1200 V 40 A SiC SBD

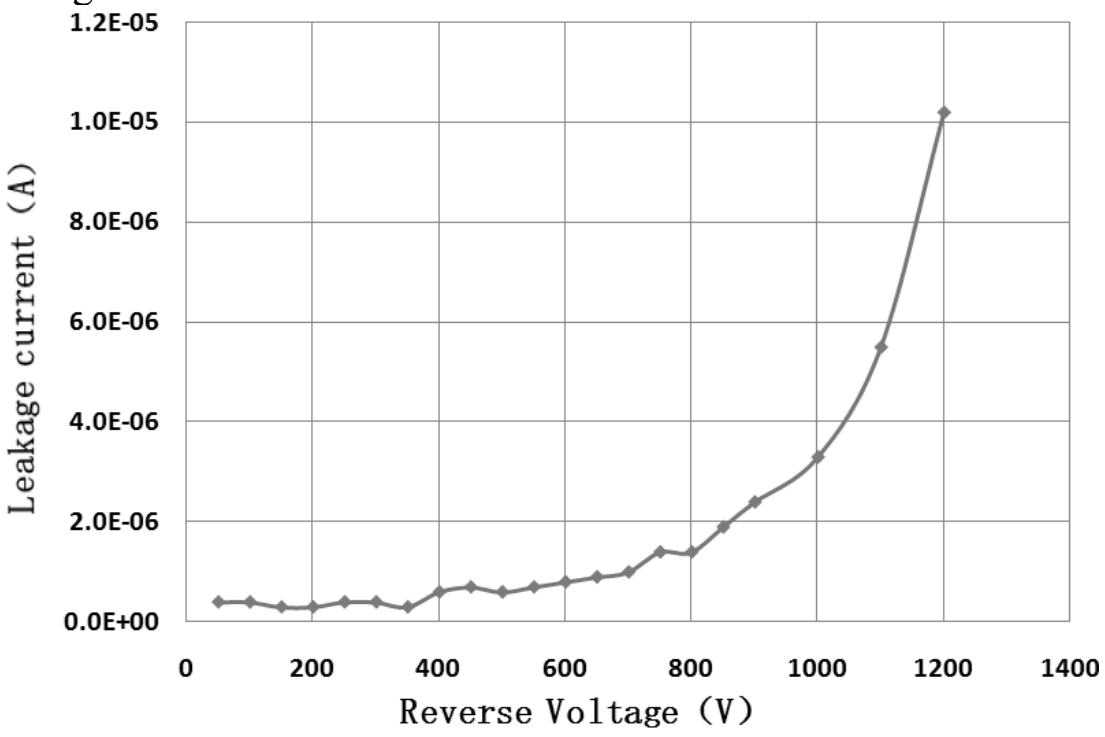

Fig. 5 Reverse I-V characteristics 1200 V 40 A SiC SBD 


\section{Conclusions}

1200 V 40 A SiC SBD devices on $n+$ conductive 4H-SiC substrates have been fabricated. The double side Au processes and the package of the SiC JBS were developed and high performance of the SiC JBS device was reported. By employing a high energy ion implantation and high temperature annealing technique, excellent characteristics were obtained. The breakdown voltage can be improved to more than $1.2 \mathrm{kV}$ depending on device guard ring termination structure. A low reverse leakage current below $4.08 \times 10^{-4} \mathrm{~A} / \mathrm{cm}^{2}$ at the bias voltage of $-1.2 \mathrm{kV}$ has been obtained. The forward on-state current was $40 \mathrm{~A}$ at $\mathrm{V}_{\mathrm{F}}=1.61 \mathrm{~V}$ at $25^{\circ} \mathrm{C}$ and $160 \mathrm{~A} / \mathrm{cm}^{2}$. The fabricated diodes can be used in high temperture, high-voltage, high-current switching test systems.

Next step is to optimize the fabrication in order to get a lower reverse leakage and higher forward conduction. Further work will focus on more extensive studies of the reverse recovery waveforms and reverse capability of the fabricated JBS diodes at higher temperature.

\section{Acknowledgments}

We would like to thank all the members of State Key laboratory of Wide-bandgap Semiconductor Power Electronics. Helps received from the wide band semiconductor R\&D department are also acknowledged. The work was supported by the National 863 Program (Grant No. 2014AA032601) from the Chinese Ministry of Science and Technology.

\section{References}

[1] M. Tarplee, V. Madangarli, T.S. Sudarshan. Current-voltage characteristics of an integrated Schottky diode. Solid-State Electronics 46 (2002) 753-757.

[2] Chen Gang, Li Zhe-yang, Bai Song, Ren Chun-jiang. Ti/4H-SiC Schottky barrier diodes with field plate and $\mathrm{B}+$ implantation edge termination technology. CHINESE JOURNAL OF SEMICONDUCTORS, Vo1. 28 No. 9, Sep., 2007, pp. 1333-1336.

[3] Dai Okamoto1, Yasunori Tanaka1, Tomonori Mizushima, et. al. 13-kV, 20-A 4H-SiC PiN Diodes for Power System Applications. Materials Science Forum Vols. 778-780 (2014) pp $855-858$

[4] Runhua Huang, Gang Chen, Song Bai, et. al. Simulation, Fabrication and Characterization of 4500V 4H-SiC JBS diode. Materials Science Forum Vols. 778-780 (2014) pp 800-803.

[5] R. Perez, N. Mestres, D. Tournier, P. Godignon, J. Millan. Ni/Ti ohmic and Schottky contacts on $4 \mathrm{H}-\mathrm{SiC}$ formed with a single thermal treatment. Diamond \& Related Materials 14 (2005) 11461149. 